\title{
EDITORIAL
}

\section{Show me the money}

\author{
Universities are charities that have a duty to solicit help to fulfil their ambitions, both in the \\ provision of education and in the conduct of research. If European higher education \\ institutions are to compete effectively on a global scale, they must become as good at \\ fundraising as their competitors in the United States.
}

In a time of increasing pressure on public funding for universities, few in the higher-education sector question the importance of philanthropic donation as a source of much needed income. Many governments, overtly or otherwise, are reducing the amount of financial support they provide to universities, and are encouraging the sector to raise the necessary investment themselves. Successful fundraising through voluntary donations means greater flexibility for a university, allowing increased investment in areas of excellence, additional support for students and the next generation of academics, and can be the sole opportunity for infrastructure development. In short, a successful fundraising campaign can provide a university with increased autonomy to control its own destiny and, as one American university fundraising office succinctly puts it, "provide the people... with a better university than they could otherwise afford". Indeed, in an era in which governments are politically compelled to define the worth of universities in terms of their economic contribution, philanthropy can also serve to protect the place of the valuable - as opposed to the practical - in our higher education institutions.

If one accepts that voluntary donations bridge the significant gap between the funds that a progressive university requires to fund their development plans and what the public purse can provide, then British and European universities face a considerable struggle if they are to remain globally competitive. Taking the United Kingdom as an example, fundraising pales in comparison to the adept efforts of American universities. Although an atypical example, Harvard University has a staggering endowment in the order of $£ 10$ billion. The approximate value of the endowment enjoyed by Oxford University is $£ 2$ billion. Perhaps a more illuminating comparison comes from an analysis of American public universities, which have more in common with British higher education institutions. In 1973, public universities in the United States received just over $10 \%$ of the amount of voluntary support per student realised by private universities. During the 1970s and 1980s, many of these institutions began professional fundraising activities and, by 2002 , had increased that proportion to $25 \%$. Of course, there are significant differences in the culture of giving between
Britain and America. In general, individual Americans give more to all causes - $1.8 \%$ of GDP compared to $0.7 \%$. Furthermore, education comes second only to religion on the list of charitable causes in the United States, receiving $14 \%$ of all donations. In stark contrast, education does not even feature on the list of main charities receiving donations in the United Kingdom.

Cultural trends aside, the potential for growth in voluntary giving to the British higher-education sector is enormous. According to a 2004 British-government-backed report (available at: http://www.dfes.gov.uk/hegateway), if British higher education institutions increased their share of individual donations to the proportions achieved in the United States, the sector would receive $£ 600$ million annually, a figure that does not include donations from foundations and corporations. Who will give? One could argue that the source of this income should be the highly educated and wealthy middle classes who have benefited enormously from the opportunities afforded to them by a university education, many of whom, evidence suggests, would be willing to support their institution if they were asked. Although significant progress has been made in fundraising in recent years, many British and European universities have not approached the solicitation of donations in the professional and systematic manner that is common in the United States.

Unlocking the full potential of this resource must be a priority in the coming years. The consequences of a delay in exploiting private income to its maximum will be the continued loss of global competitiveness, a discrepancy that is poised to intensify in the future. According to the Rand Council for Aid to Education, American citizens have doubled annual donations to their higher education sector in the past decade (to $\$ 24$ billion in 2003). It is also estimated that this figure could double again in the next decade, and again by 2020 as affluent Americans bequeath their accumulated assets - estimated at $\$ 41$ trillion - to future generations. In the face of such enormous resources becoming available to their American counterparts, British and European higher education institutions must accept they can no longer rely on government and that the exploitation of philanthropy through professional fundraising has become an option that can no longer be ignored. 